\title{
Translational initiation regulated by ATM in dendritic cells development
}

\author{
EY So ${ }^{1}$ and T Ouchi ${ }^{* 1}$
}

Ataxia telangiectasia mutated (ATM) protein has been implicated in multiple pathways such as DNA repair, cell cycle checkpoint, cell growth, development, and stem cell renewal. In this study, we demonstrate evidence that ATM is involved in granulocyte macrophage colony-stimulating factor (GM-CSF)-induced dendritic cell (DC) development from bone marrow (BM) cells. Inactivation of ATM protein results in decreased BM proliferation, leading to reduced DC development and their activity for T cell activation. Expression of Jak2, STAT5, and mTOR is suppressed in both wild-type and ATM-null BM prior to GM-CSF stimulation. Activation of those proteins is delayed and prolonged hypophosphorylation of 4EBP1 is observed in ATM-null BM when treated with GM-CSF, although Erk and p38 are similarly expressed and activated in both wild-type and ATM-null BM cell types. Akt is also suppressed in wild-type BM, and transduction of constitutively active Akt or STAT5 in ATM-null BM restores DC development. Together, these results illustrate that ATM deficiency causes impaired initiation of protein translation in BM, leading to immature development of DC.

Cell Death and Disease (2014) 5, e1418; doi:10.1038/cddis.2014.362; published online 11 September 2014

Dendritic cells (DC), like macrophages, are professional antigen-presenting cells (APCs) and play a critical role in the initiation and progress of immune response against foreign pathogens. Stimulation of bone marrow (BM) with granulocyte macrophage colony-stimulating factor (GM-CSF) induces their differentiation to classical/conventional DC (CDC), ${ }^{1}$ or Flt3-ligand (Flt3-L) induces both $\mathrm{CDC}$ and plasmacytoid DC. ${ }^{2}$ Also, low percentages of BM cells are differentiated into macrophage-like cells (BMMP), which are strongly attached in culture plates. ${ }^{1}$ During differentiation, the expression of major histocompatibility complex (MHC)II proteins and T-cell costimulatory molecules, such as CD40 and CD86, are increased on cell surface of DC, leading to generation of APCs. ${ }^{3}$

The ataxia-telangiectasia mutated (ATM) gene encodes a $350 \mathrm{kD}$ Ser/Thr kinase, which is a member of the phosphatidylinositol 3'-kinase (PI3K)-related kinase (PIKK) family, and it plays a critical role in the maintenance of genome integrity. ${ }^{4}$ The ATM protein participates in regulating cell cycle checkpoint in response to DNA damage and oxidative stress and modulates intracellular levels of reactive oxygen species. ${ }^{5,6}$ Previous reports showed that the expression of ATM is differentially regulated during development of lymphocytes and mice deficient for the ATM gene display impaired T-cell development, leading to decreased numbers of total T cells. ${ }^{7-9}$ In the context of cell differentiation, it has been shown that ATM is essential for osteoblast differentiation by regulation expression of osteoblast-specific transcription factors. ${ }^{10}$
There are accumulating evidences indicating that ATM is involved in development of $\mathrm{T}$ and $\mathrm{B}$ lymphocyte. ${ }^{11-13}$ However, it remains unclear how this protein plays a role in developing APCs, such as DC and macrophages. Given that APCs are essential for inflammatory and immune responses to maintain homeostasis, ${ }^{14}$ it is quite important to determine the mechanism of their development from BM. In this study, we have investigated the in vivo function of ATM in DC development and explored the novel roles of the protein. We found that levels of ATM protein remarkably increased (over 100 fold) when BM are stimulated with GM-CSF through mainly post-transcriptional regulation. Also, we generated evidence that ATM's essential roles in development and maturation of DC when BM are treated by GM-CSF using both ATM-null BM and an ATM-inhibitor (KU55933). These results clearly illustrate novel and non-DNA damage functions of ATM in determination of cell differentiation from hematopoietic progenitors.

\section{Results}

ATM expression during the development of DC in BM culture. Expression of ATM transcripts is differentially regulated in different tissues. ${ }^{13}$ Earlier studies have shown that levels of ATM protein are higher in the proliferative myoepithelial cells of breast ducts than those in resting stage. ${ }^{15}$ Other studies have shown that ATM protein dramatically increases in peripheral blood mononuclear cells

\footnotetext{
${ }^{1}$ Department of Cancer Genetics, Roswell Park Cancer Institute, Buffalo, NY, USA

*Corresponding author: T Ouchi, Department of Cancer Genetics, Roswell Park Cancer Institute, Elm and Carlton Streets, Buffalo, NY 14263, USA. Tel: +1 716845 7173; Fax: +1 716845 1689; E-mail: Toru.Ouchi@RoswellPark.org

Abbreviations: ATM, ataxia telangiectasia mutated; GM-CSF, granulocyte macrophage colony-stimulating factor; Jak2, Janus Kinase 2; STAT5, signal transducer and activator of transcription 5; mTOR, mammalian target of rapamycin; DC, dendritic cell; BM, bone marrow; 4EBP1, eukaryotic translation initiation factor 4E-binding protein 1; Erk, extracellular signal-regulated kinase; MHC, major histocompatibility complex; APCs, antigen-presenting cells; NCS, neocarzinostatin; SMC-1, structural maintenance of chromosomes protein 1; Flt-3L, FMS-like tyrosine kinase 3 ligand; PIKK, phosphoinositide 3-kinase-related kinase; elF4E, eukaryotic translation initiation factor $4 \mathrm{E}$

Received 14.2.14; revised 24.6.14; accepted 01.7.14; Edited by G Raschellà
} 
in response to phytohemagglutinin without alterations in levels of ATM mRNA and the protein stability. ${ }^{11}$ We first examined if the expression of ATM is regulated during development of BM. As shown in Figure 1a, immunoblot analysis indicates that ATM protein is not detected in BM at Day 2 (D2), but weakly expressed in D2 macrophage (MP). Levels of ATM in both cell types are further increased by D4, and sustained until D5. Interestingly, ATM mRNA was detected throughout GM-CSF treatment, suggesting that levels of the protein are regulated by posttranscriptional mechanism. We asked whether these undetectable levels of ATM protein are because of increased protein degradation by proteasome. However, when BM at D2 were treated with two different concentrations of proteasome inhibitor, MG132, ATM protein levels did not increase (Figure 1b). These results support a mechanism of posttranscriptional regulation of the protein in BM.

When BM at D6 were washed and re-stimulated with GM-CSF or neocarzinostatin (NCS, radio mimetic agents causing DNA double-strand breaks), ATM was rapidly phosphorylated (Figure 1c). Interestingly, SMC1 protein, a known ATM substrate under conditions of DNA stress, was phosphorylated only by NCS, not by GM-CSF, suggesting that ATM pathway activated by GM-CSF is a

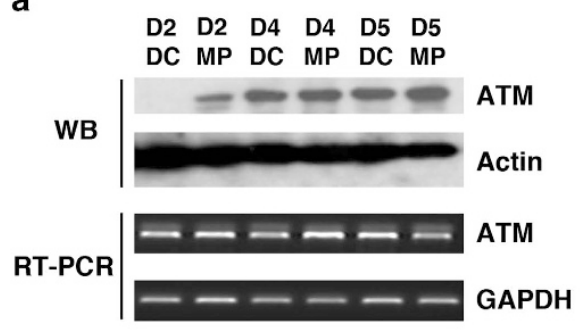

C

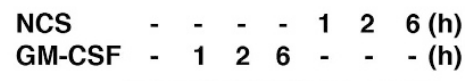

b

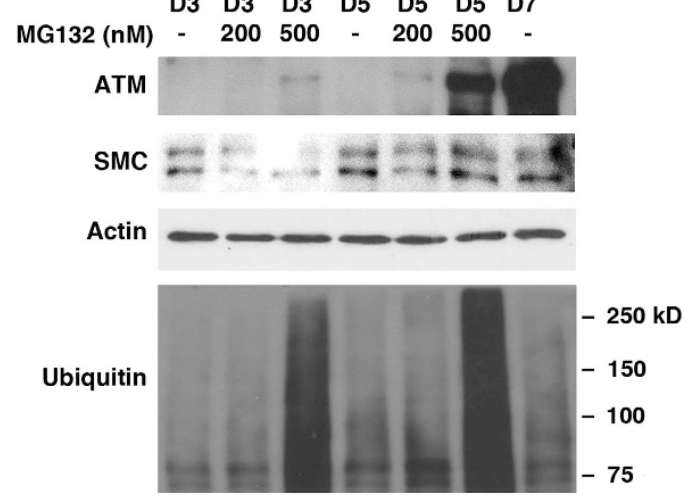

d

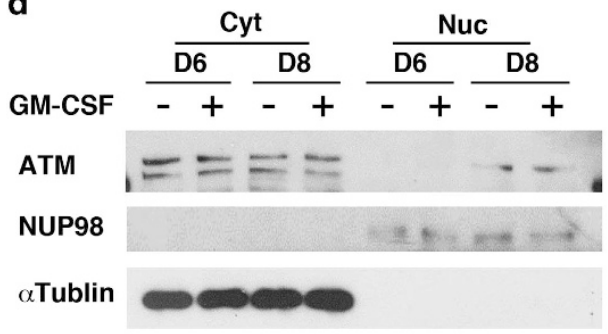

e

$\begin{array}{lccccccccccccc}\text { KU55933 } & - & - & - & - & - & - & - & + & + & + & + & + & + \\ \text { NCS } & - & - & - & - & 1 & 2 & 5 & - & - & - & 1 & 2 & 5 \\ \text { GM-CSF } & - & 1 & 2 & 5 & - & - & - & 1 & 2 & 5 & - & - & -\end{array}$

ATM-P $\quad$ Hat

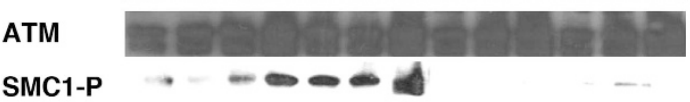

SMC1-P

SMC1

Actin

Figure 1 The phosphorylation and expression of ATM in GM-CSF-induced BM. (a) BM precursors were purified from C57BL/6J male mice and developed into DC and MP using GM-CSF $(20 \mathrm{ng} / \mathrm{ml}$ ) for indicated times, as previously published. Suspended and weakly attached cells were harvested by repeated pipetting and strongly attached cells were detached from plates using scrapper. Total lysates and total RNA were isolated from same cell populations, and then subjected to western blot and RT-PCR analysis, respectively. Lane 1. suspended and attached cells (DC) of D2; lane 2. strongly attached cells (macrophages) of D2; lane 3. suspended and attached cells of D4; lane 4. strongly attached cells of D4; lane 5. suspended and attached cells of D5; lane 6. strongly attached cells of D5. Actin protein and GAPDH transcript were used as internal control to validate ATM expression in these cells. (b) BM were treated with MG132 (DMSO only, 50 and $200 \mathrm{nM}$ ) at D2. After $24 \mathrm{~h}$, cells were harvested and then subjected to western blot analysis of ATM and SMC1 expression. Total lysate from D3, D5, and D7 BM were studied. (c) D6 BM were washed and cultured in GM-CSF-free media for $24 \mathrm{~h}$, and then re-treated with GM-CSF $(20 \mathrm{ng} / \mathrm{ml})$ or NCS $(0.5 \mu \mathrm{g} / \mathrm{ml})$ for indicated times. (d) Nuclear extract (Nuc) and cytoplasmic extract (Cyt) were isolated from D6 or D8 BM after starvation and re-culture with $(+)$ or without $(-)$ GM-CSF. Antibodies against NUP98 and a Tubulin were used as references of nuclear and cytoplasmic extract, respectively. (e) After starvation in GM-CSF-free media for $24 \mathrm{~h}$, D6 wild-type BM cells were re-cultured with GM-CSF (20 ng/ml) or NCS (0.5 mg/ml). DMSO ( - ) or KU55933 $(+, 5 \mathrm{mM})$ was added and cultured at indicated times 
different from the one by DNA stress. We also observed that the levels of ATM protein are increased by GM-CSF in $6 \mathrm{~h}$, indicating that GM-CSF regulates both ATM activity and its protein level.

We next studied the subcellular localization of ATM in D6 and D8 BM (Figure 1d). The protein was predominantly detected in the cytoplasmic fraction of D6; however, it was detected in the nuclear fraction at D9. This specific localization was not changed by GM-CSF stimulation. It has been demonstrated that NCS treatment rapidly induces full activation of nuclear ATM. ${ }^{16,17}$ Our results show that much stronger phosphorylation of ATM is observed at $6 \mathrm{~h}$ after NCS treatment, although $\mathrm{SMC} 1$ is phosphorylated as early as at $1 \mathrm{~h}$ (Figure 1c). Thus, cytoplasmic ATM could be differentially activated from the nuclear ATM. These observations implicate that ATM may function in cytoplasm at early developmental stage of DC.

GM-CSF-induced in vitro development of DC was impaired in ATM-null BM. To further understand the roles of ATM in the DC development, we determined the ability of ATM-null BM to develop DC in comparison with wild-type BM. We analyzed wild-type and ATM-null BM cell cultures at different time points of GM-CSF treatment (D2, D4, D6, and D8) by double staining for $\mathrm{CD} 11 \mathrm{C}$ and $\mathrm{MHCll}$ to detail $\mathrm{DC}$ differentiation (Figure 2a). There was no significant difference in levels of expression of both CD11c and $\mathrm{MHCI}$ proteins at D2 between wild-type and ATM-null BM. However, the appearance of matured DC is clearly delayed in ATM-null BM from D4 to D8. These results suggest that ATM is involved in DC development.
Potential roles of ATM in DC development were further studied by treating wild-type BM with ATM inhibitor, KU-55933 $(\mathrm{KU})$, which has been shown to inhibit cell-stress-induced ATM phosphorylation and subsequent p53 phosphorylation. ${ }^{18}$ We treated BM with $\mathrm{KU}(5 \mu \mathrm{M})$, and studied the development of $\mathrm{DC}$ by qualifying levels of $\mathrm{CD} 11 \mathrm{C}$ and $\mathrm{MHCll}$ proteins (Figure 2b), or CD11c and CD86 (Supplementary Fig S1) that are additional DC maturation markers. ${ }^{19}$ These results indicate that treatment with $\mathrm{KU}$ inhibited GM-CSF-induced DC development of wild-type BM, supporting that ATM is involved in GM-CSF-induced development of DC.

ATM-null BM show increased apoptosis and lowered ability of T-cell activation. To investigate the effects of ATM deficiency on DC development, we characterized cell proliferation and basal levels of apoptosis at different time points of the culture (D3, D6, and D9) (Figure 3a). Basal levels of apoptosis determined by Annexin $\mathrm{V}$ staining did not change significantly in wild-type BM (16.8-13.4\%), but they increased in ATM-null BM (14.6-24.5\%) from D3 to D9. Consistent with these results, ATM-null BM showed significantly lower cell proliferation throughout the cell culture, compared with wild-type BM (Figure $3 b$ ), and these results indicate that increase in apoptosis results in the decreased proliferation of ATM-null BM.

$\mathrm{MHCll}$ present on the surface of APCs binds antigenic peptides, followed by association with TCR and subsequent stimulation of $\mathrm{T}$ cells. ${ }^{20}$ Given that BM obtained from ATMdeficient mice express lower levels of $\mathrm{MHCll}$ after GM-CSF treatment, we reasoned to perform in vitro mixed lymphocyte

a
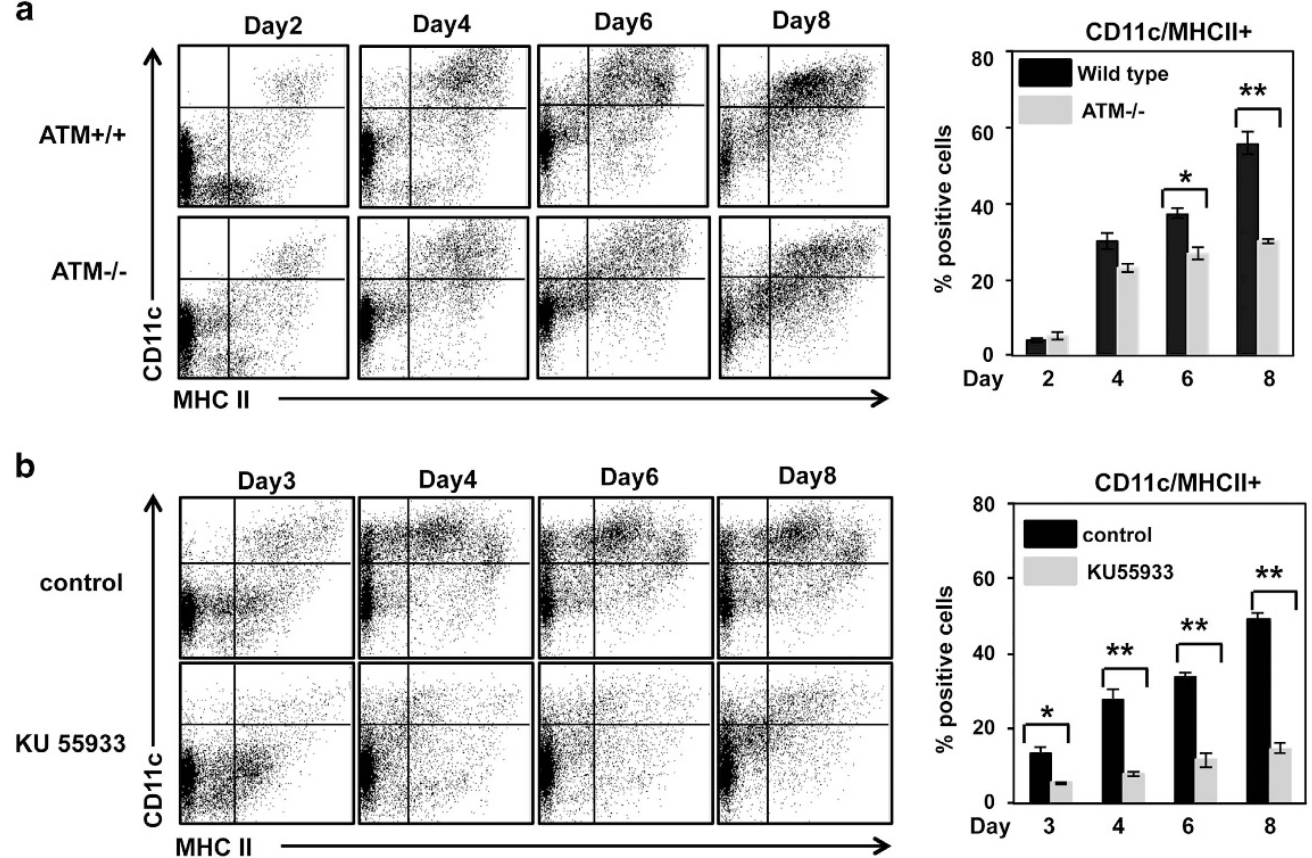

Figure 2 GM-CSF-induced in vitro development of DC was impaired in ATM-null BM. (a) BM were isolated from ATM-null (ATM-/-) or wild-type (ATM + / +) mice, and developed into DC by GM-CSF treatment. (b) BM from wild-type mice were cultured in GM-CSF with or without KU-55933 $(5 \mu \mathrm{M})$. Cells were harvested on indicated days and stained with anti-CD11C-FITC and anti-MHCII (I-A/I-E)-APC antibodies. Percentage of DC (CD11C ${ }^{+} / \mathrm{MHCII}^{\text {Med-High }}$ ) to total cells was analyzed by flow cytometry. Left panel; flow cytometry results. Right panel; a Bar graph showed the average percentage of $\mathrm{CD} 11 \mathrm{c} / \mathrm{MHCll}$ positive cells. Experiments were performed by three independent experiments. All data are present as mean \pm S.E. of three replicates. ${ }^{*} P<0.05 ;{ }^{* \star} P<0.01$ 


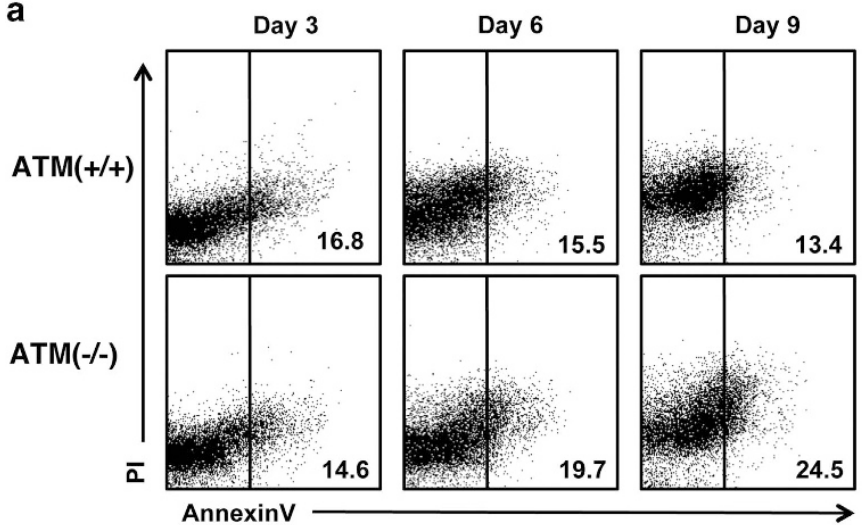

b

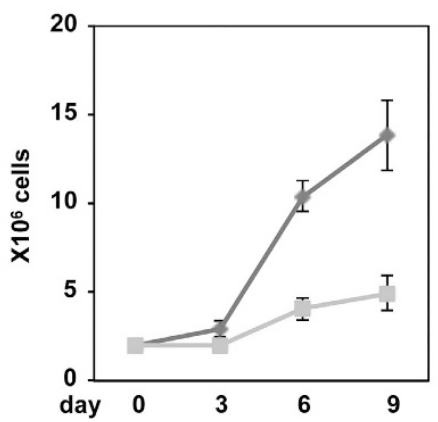

C

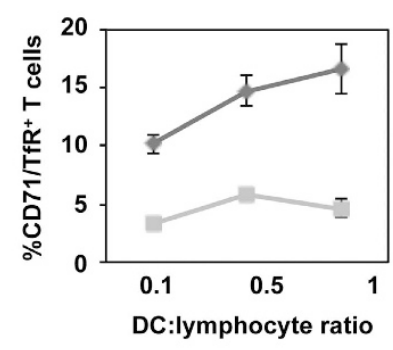

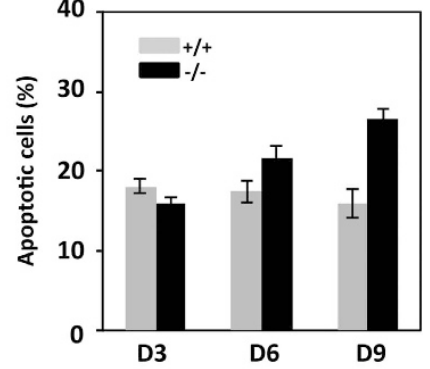

Figure 3 The effect of ATM deficiency on cell growth and immune functions of DC. BM from wild-type and ATM-null mice were cultured for indicated days with GM-CSF $(20 \mathrm{ng} / \mathrm{ml})$, followed by Annexin V staining to analyze their (a) apoptosis and (b) proliferation. (c) BM from wild-type or ATM-null mice were cultured in RPMI 10 media containing GM-CSF $(20 \mathrm{ng} / \mathrm{ml})$ for 9 days. DC were harvested and co-cultured for 4 days with allogeneic lymphocytes obtained from SJL/J mice in indicated ratios of $\mathrm{DC} /$ lymphocytes. Data represent the percentage of $\mathrm{CD}_{7}{ }^{+}$cells / total $\mathrm{CD}^{+}{ }^{+} \mathrm{T}$ cells. Experiments were performed in duplicates and repeated at least three times

reaction assay ${ }^{21}$ to study the ability of both wild-type and ATMnull $D C$ to activate allogeneic $T$ cells. As the iron transferrin receptor CD71 has been well characterized to be upregulated on activated $\mathrm{T}$ cells, ${ }^{22,23}$ we analyzed the expression of cell surface CD71 on CD3 T cells by GM-CSF-induced DC (Figure 3c). Allogeneic lymphocytes isolated from SJL/J mice were stimulated by either wild-type or ATM-null DC at different ratio (DC:lymphocytes). Cell surface expression of CD71 was analyzed by flow cytometry. When T cells were stimulated with DC from wild-type BM culture, CD71 expression was significantly increased. However, with DC from ATM-null BM, increase in levels of CD71 was much lower. These results indicate that ATM deficiency not only causes reduced cell proliferation and GM-CSF-induced development of DC but also results in impaired activity of DC to activate T cells, conceivably because of reduced levels of $\mathrm{MHCII}{ }^{\text {High }} \mathrm{CD} 11 \mathrm{c}^{\text {High }} \mathrm{DC}$.

It has been well established that lipopolysaccharide (LPS) treatment remarkably increases the population of mature DC from BM culture in vitro when BM are treated with GM-CSF, and LPS-induced maturation markedly increases $\mathrm{MHCI}$ expression and the ability of DC to stimulate T-cell responses in vitro. ${ }^{24,25}$ Therefore, we explored whether ATM deficiency affects LPS-induced DC maturation. BM at D9 were further treated with LPS for $24 \mathrm{~h}$, and then increased population of matured DC (MHCII High $\left.\mathrm{CD} 11 \mathrm{c}^{\text {High }}\right)$ was quantified (Figure 4). In wild-type BM at D9, population of matured DC was $25.9 \%$, but it was further increased by LPS treatment (69.7\% (2.7 fold) and $71.2 \%(2.8$ fold $)$ ) by 1 and $2 \mu \mathrm{g} / \mathrm{ml}$, respectively.
Population of ATM-null matured DC at D9 were lower (17.8\%) than those of wild-type BM; however, it was increased by 1 and $2 \mu \mathrm{g} / \mathrm{ml}$ of LPS treatment (53.2\% (3.0 fold) and $63.4 \%$ (3.6 fold), respectively). Consistent with this finding, KU55933 treatment did not significantly inhibit LPS-induced maturation (Supplementary Fig S2). These results indicate that, in response to GM-CSF, total numbers of ATM-null DC are lower than those of wild-type DC; however, ATM-null DC can be similarly maturated by LPS treatment. These results suggest that ATM is involved in the early stage of DC development, rather than in their maturation induced by LPS.

ATM-mediated signaling is required for optimal activation of Akt by GM-CSF during BM development. Previously, Xie et al. ${ }^{26}$ showed that Erk and PI3K/Akt signaling pathways play critical roles in the development of human monocytederived DCs. To investigate whether ATM deficiency can modulate the expression and activation of Akt, Erk, and p38 during the development of DC, we examined their protein levels and phosphorylation at different time points after GM-CSF treatment.

As shown in Figure 5a, Akt was increased from D2 to D4 in wild-type BM, and sustained by D9. Phosphorylation of Akt was detected at D6 and D9. Increase in the phosphorylation of Akt was slightly reduced in wild-type BM treated with KU55933, although protein levels are similarly induced from D2 to D4. Levels of Erk and p38 proteins did not significantly change from D2 to D9. Phosphorylation of Erk decreased from 


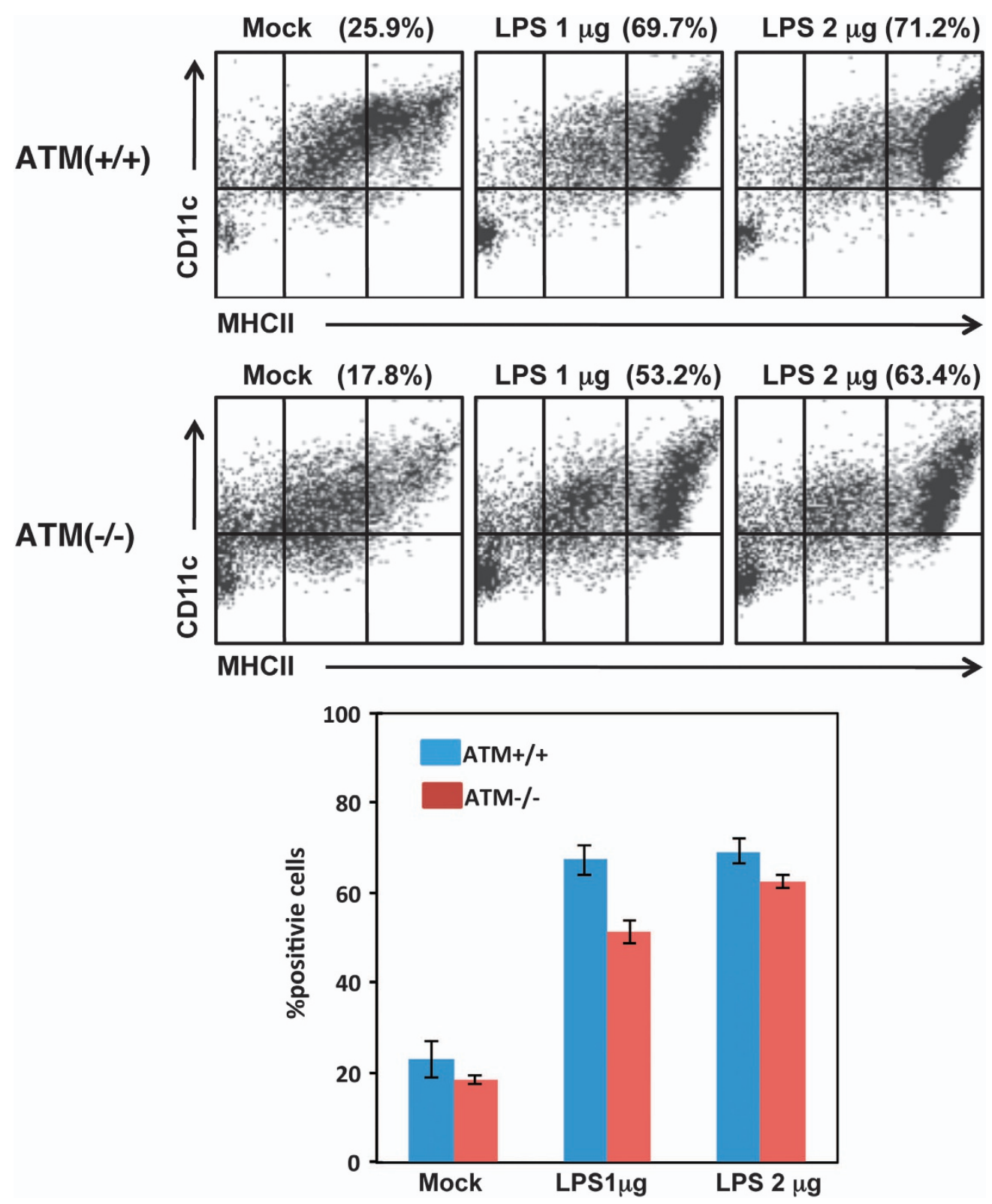

Figure 4 LPS-induced DC maturation in both wild-type and ATM-null BM cultures. Wild-type and ATM-null BM at D9 were harvested, followed by treatment with LPS ( 1 and $2 \mu \mathrm{g} / \mathrm{ml})$ for additional $24 \mathrm{~h}$. The percentage of maturated BMDC was quantified by ratio of mature $\left(\mathrm{CD} 11 \mathrm{c}^{+} \mathrm{MHCll}^{\text {High }}\right)$ to immature + mature DCs $\left(\mathrm{CD} 11 \mathrm{C}^{+} \mathrm{MHCII}^{\text {Med-High }}\right)$. A representative of two independent experiments was shown

D6 to D9 in non-treated and KU55933-treated wild-type BM. Phosphorylation of p38 was not detected in both cells.

Next, we asked if these kinases are differentially regulated in ATM-null BM (Figure 5b). We found that Akt is not expressed in BM of D0, and increased at D3 in both wild-type and ATM-null $B M$, although levels of the protein in ATM-null BM is lower in ATM-null BM at D3. Protein levels were further increased in both cell types from D6 to D9, but those were slightly lower in ATM-null BM. Erk and p38 were similarly expressed in both wild-type and ATM-null BM from D0 to D9. Phosphorylation of Erk was strongly induced at D3 in both cell types, and reduced from D6 to D9, and no significant difference was observed. Phosphorylation of p38 was weakly induced from D0 to D3 in both cell types, and sustained until D9.
We then explored whether activation of Akt is important for DC development (Figure 5c). When wild-type BM (D0) were treated with GM-CSF together with Akt inhibitor, or KU55933, population of $\mathrm{MHCII}{ }^{\mathrm{High}} \mathrm{CD} 11 \mathrm{c}^{\mathrm{High}}$ at D9 was significantly reduced, supporting a notion that activation of Akt is critical for DC development from BM.

We tested if exogenous expression of Akt rescues DC development from ATM-null BM culture. Wild-type or ATMnull BM at D2 were infected with retrovirus expressing GFPtagged constitutively active $\mathrm{Akt}^{27}$ (Figure 5d), At D6, BM were harvested, and GFP-negative (not infected) and GFP-positive (Akt-infected) cells were analyzed for $\mathrm{MHCll}$ expression. We found that the GFP ${ }^{+} / \mathrm{ATM}$-null BM highly express MHCII similar with $\mathrm{GFP}^{+}$wild-type BM (73.4 versus $\left.78.2 \%\right)$. These 
a

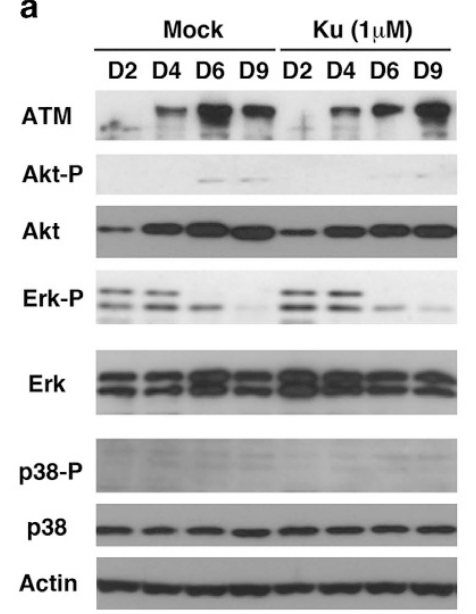

b

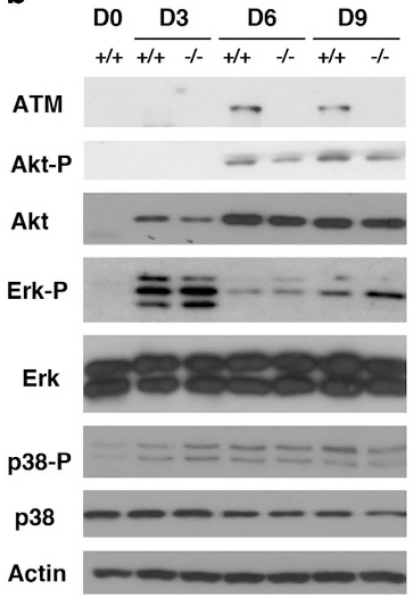

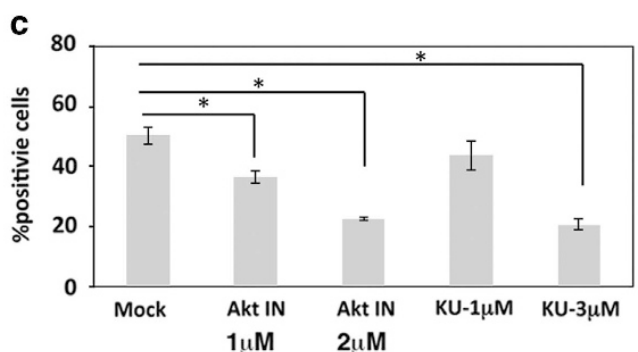

d
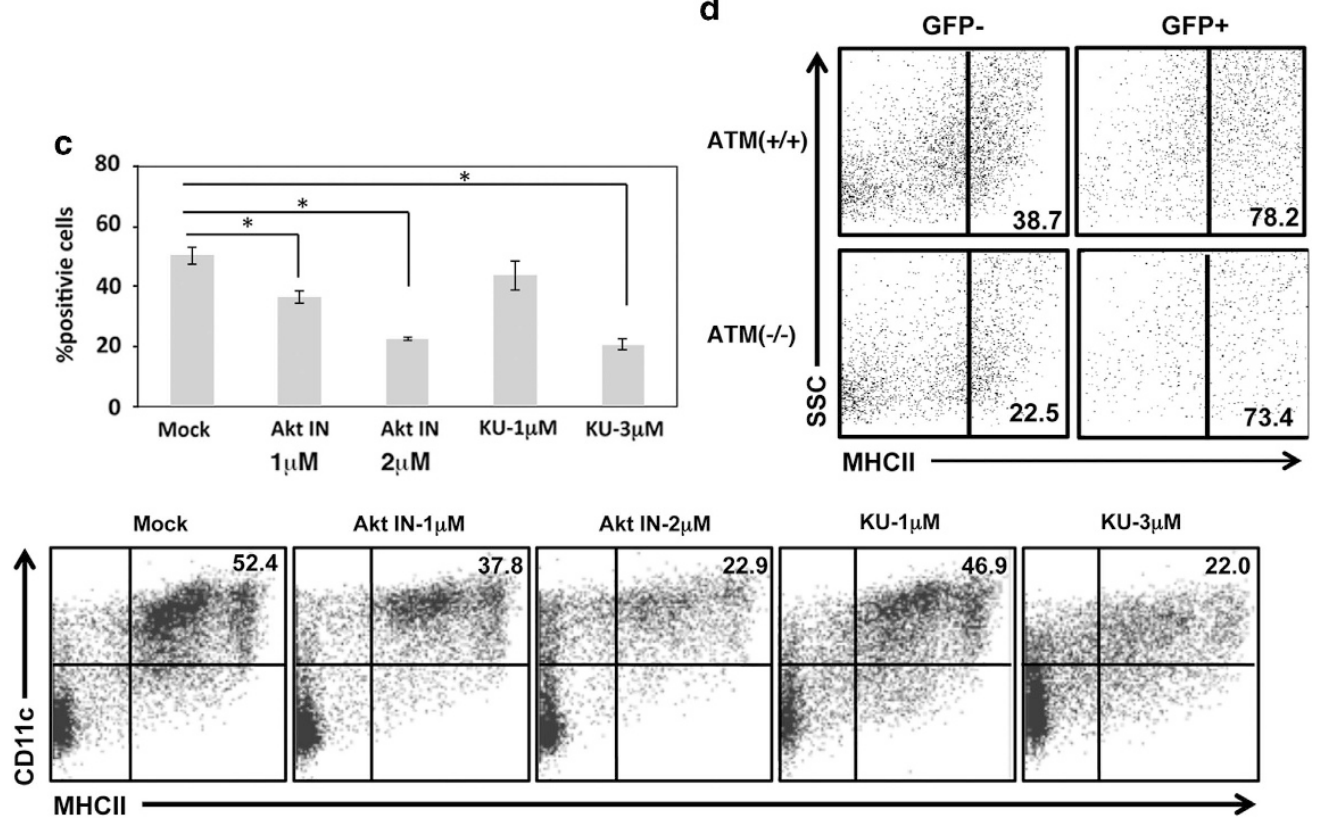

Figure 5 The effect of ATM deficiency and KU-55933 on GM-CSF-induced kinase signaling in BM culture. (a) Wild-type BM were cultured in GM-CSF-containing media with or without $\mathrm{KU}(1 \mu \mathrm{M})$ for 9 days. (b) Wild-type and ATM-null BM were cultured and harvested at D0, D3, D6, and D9. Cells were then lysed and total cell extracts were subjected to SDS-PAGE and western blotting assay. Phospho-protein (Akt at Ser473; Erk at Tr202/Tyr204; p38 at Thr180/Try182) and total proteins were detected. Actin protein was used as loading control. (c) Wild-type BM were cultured in the presence of GM-CSF with or without Akt inhibitor (Akt IN) or KU55933 (KU) at indicated concentration. Cells were harvested at D9 and subjected to flow cytometric analysis after staining with anti-CD11c/MHCII. (d) BM were infected with retrovirus expressing constitutively active Akt-IRES-GFP at D3, and BM were harvested at D6. GFP-negative (Akt not-expressing) and GFP-positive (Akt expressing) cells were sorted and MHCII expression were analyzed. Data were expressed by a percentage of $\mathrm{MHCll}+$ cells and representative of two independent experiments

results indicate that activation of Akt is crucial for GM-CSFinduced DC development.

The expression and activation of STAT5 by GM-CSF is delayed in ATM-null BM. Recent reports have described that the GM-CSF/Jak2/STAT5 arm of signaling is essential to determine the DC differentiation from progenitor cells. ${ }^{28} \mathrm{We}$ found that Jak2 and STAT5 proteins are undetectable at early time point of GM-CSF treatment of wild-type BM, and appear at D5 and D6, respectively (Figure 6a). Expression of these proteins was delayed in ATM-null BM, thus we found that these proteins appear at D6 and D7. Tyrosine phosphorylation of Jak2 in wild-type and ATM-null BM was detected at D5, although Jak2 protein was not detected in ATM-null BM at D5. Levels of Jak2 phosphorylation in ATMnull BM were lower than that in wild-type cells at D5 and D6. At D7 and D8 when Jak2 protein is similarly expressed in both cell types, no significant difference of tyrosine phosphorylation of Jak2 was observed. Protein expression of STAT5 was detected at D6 and increased at D7 in wild-type BM. In ATM-null BM, it was expressed at D7 to the similar levels in wild-type BM. Tyrosine phosphorylation of STAT5 in ATM-null $\mathrm{BM}$ was lower than that in wild-type BM at D7 and D8.

As shown in Figure 6b, STAT5A and Akt1 mRNAs were similarly expressed at D3, D6 and D8, and no differences were found between wild-type and ATM-null BM, suggesting that 
a

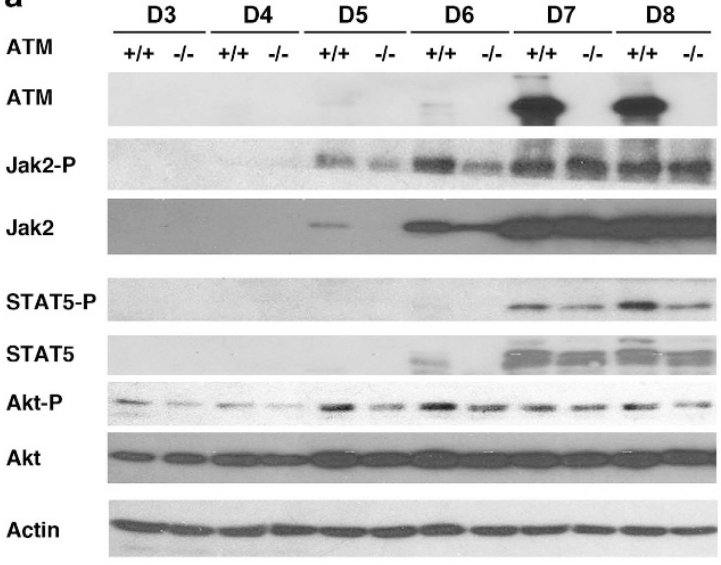

b

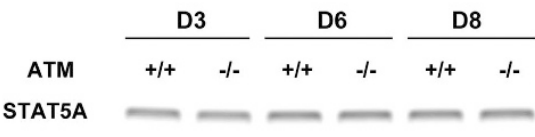

Akt1

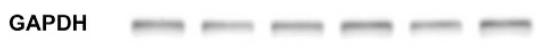

C

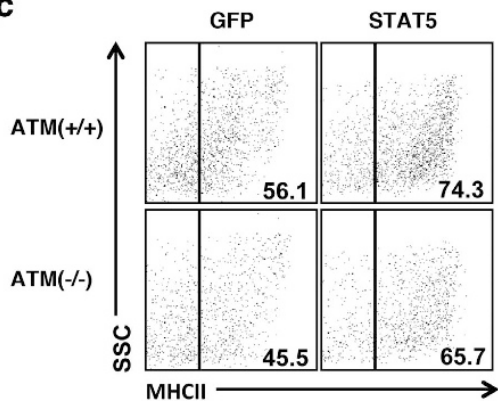

Figure 6 Essential roles of STAT5 in DC development. (a) BM were isolated from wild-type $(+/+)$ or ATM-null mice $(-/-)$, then cultured in GM-CSF-containing media for indicated days. Cells were then lysed and total cell extracts were subjected to SDS-PAGE and western blotting assay with antibodies against phospho-proteins (Jak2 at Tyr1007/1008; STAT5 at Tyr649; Akt at Ser473) and total proteins. Actin protein was used as loading control. (b) Total RNA was isolated from wild-type and ATM-null BM at indicated days, followed by RT-PCR to examine indicated gene expression. The level of GAPDH mRNA was used to validate control gene expression. (c) BM at D3 were infected with retrovirus expressing GFP or STAT5-GFP (STAT5), and cultured until D8. Percentage of MHCIIMed-High of GFP-positive cells was analyzed and shown. Data were representative of two different experiments

levels of these proteins are regulated by posttranscriptional mechanism.

To test if induced expression of STAT5 at D5 is critical for development of DC, wild-type or ATM-null BM at D3 were infected with retrovirus expressing GFP only or GFP-STAT5 and expression of MHCII was studied by FACS analysis at D8 (Figure 6c). Percentage of GFP ${ }^{+} / \mathrm{MHCII}^{\text {high }} \mathrm{DCs}$ in wild-type and ATM-null BM was $56.1 \%$ and $45.5 \%$, respectively. When GFP-STAT5 was expressed, this population in wild-type and ATM-null BM was increased to $74.3 \%$ (1.3 fold increase) and $65.7 \%$ (1.4 fold increase), respectively. These data suggest that the expression of STAT5 at D5 is important for the induction of $\mathrm{MHCll}$ in $\mathrm{BM}$ that is crucial for the development of matured DC.

ATM is required for translation initiation by GM-CSF during development of DC. Previous studies have demonstrated that both ATM and mTOR phosphorylate 4E-binding protein1 (4EBP1) in response to insulin, ${ }^{12}$ suggesting that ATM may collaborate with Akt/mTOR to promote the efficient translation when BM are stimulated with GM-CSF. Thus, we studied whether ATM regulates both formation of elF4E/ 4EBP1 complex and phosphorylation of 4EBP1 during development of DC.

Wild-type and ATM-null BM were collected, followed by m7-GTP-sepharose pull-down assay (Figure 7a). Immunoblot analysis showed that two forms of 4EBP1 (a hypo-phosphorylated $\alpha$ and phosphorylated form $\beta$ ) bind to elF-4F. Of note, a hyper-phosphorylated form of 4EBP1 $(\gamma)$ does not bind to elF4E. ${ }^{29}$ At D6, $\alpha$ form of 4EBP1 bound to elF4E in wild-type $B M$ is much lower than those in ATM-null BM, suggesting that 4EBP1 is highly phosphorylated in wild $\mathrm{BM}$ at $\mathrm{D} 6$ and protein translation is activated. Thus, protein translation in ATM-null
$\mathrm{BM}$ at D6 is not as active as that in wild-type BM. At D7 and D8, similar amount of $\beta$ form of 4EBP1 was found to associate with elF4E.

We next detailed whether GM-CSF stimulation differentially regulates elF4E interaction with 4EBP1 in wild-type and ATM-null BM. Both BM were collected and washed with PBS and maintained in media without GM-CSF for $24 \mathrm{~h}$ (Figure $7 \mathrm{~b}$, $\mathrm{GM}(-))$. Cells were then treated with $\mathrm{GM}-\mathrm{CSF}$ for $6 \mathrm{~h}$ $(\mathrm{GM}(+))$. elF4E was pulled down and elF4E/4EBP1 complex formation was studied by immunoblot analysis. In wild-type BM obtained at D6, elF4E formed a complex with $\beta$ form of 4EBP1 in GM-CSF( - ) media. In contrast, in ATMnull BM at D6, elF4E predominantly associated with $\alpha$ form of 4EBP1. At D8, elF4E binds to $\beta$ form of 4EBP1 in both cell types. After GM-CSF stimulation, elF4E binds to $\beta$ form of 4EBP1 in wild-type BM; however, elF4E still binds to $\alpha$ form of 4EBP1 in ATM-null BM, suggesting that the initiation of protein translation is not activated by GM-CSF in ATM-null BM at D6. At D8, elF4E binds to $\beta$ form of 4EBP1 in both cell types. These results provide in vivo evidence that protein translation is at least in part inhibited in ATM-null BM until D6.

BM stimulated with GM-CSF were further analyzed for protein expression and phosphorylation of Akt and mTOR (Figure 7c). mTOR protein was not detected in both wild-type and ATM-null BM at D3. We then found that mTOR is expressed in wild-type BM at D6. It is barely expressed in ATM-null BM, and then detected at D8, although the levels were lower than those of wild-type BM. Phosphorylation of mTOR at Ser2481 was induced upon GM-CSF stimulation in BM at D6 in wild-type BM, but it was significantly weak in ATMnull BM at D6. Interestingly, phosphorylation of mTOR was observed at D8 in a GM-CSF-independent manner in both 
a

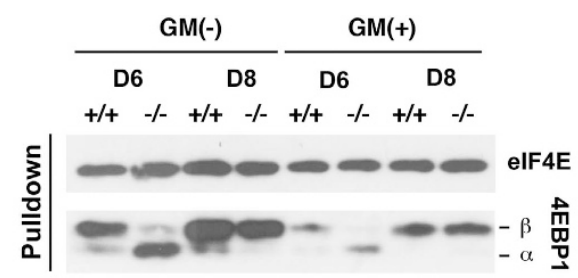

b
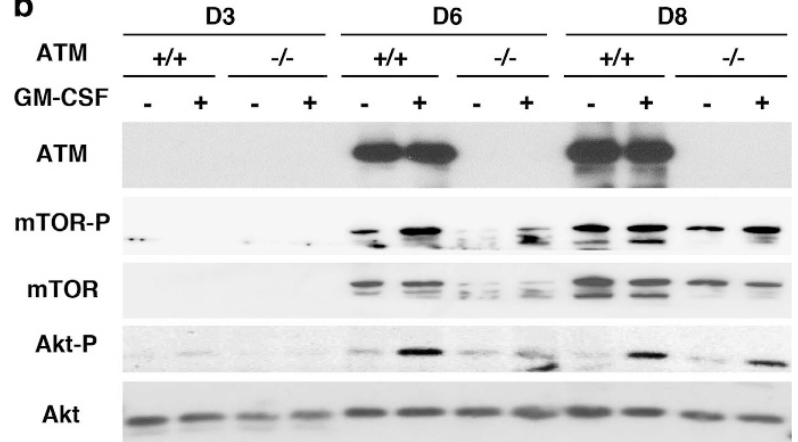

Actin

Figure 7 ATM is required for the phosphorylation of 4EBP1 and expression of mTOR. (a) BM were harvested at D6 and D8, and then cultured in GM-CSF-free media. After $24 \mathrm{~h}$, cells were re-treated with (GM +) or without GM-CSF (GM - ) for $6 \mathrm{~h}$. Total lysate was mixed with m7-GTP-sepharose and then subjected to pulldown assay, followed by immunoblot analysis of eIF4E and 4EBP1. (b) Total lysates of wild-type (ATM $+I+$ ) or ATM-null (ATM $-I-)$ were prepared at D3, D6, and D8, followed by western blot assay of protein levels of mTOR, Akt, and phosphorylated mTOR (Ser2481, S2481P) and Akt (Ser487, S487P). Actin serves as a loading control. Three experiments were performed independently

wild-type and ATM-null BM, although it was lower in the latter. Taken together, these results indicate that protein translation does not properly function in ATM-null BM, causing insufficient DC development.

\section{Discussion}

It has been well demonstrated that the primary function of ATM protein is to integrate cellular responses to DNA doublestrand breaks, which are caused by genotoxic stimuli, leading to activation of the kinase and downstream signaling pathways, such as cell cycle checkpoints and apoptosis. ${ }^{30}$ ATM deficiency causes Ataxia Telangiectasia that is characterized by cerebellar deterioration, oculocutaneous telangiectasia, immunodeficiency, genome instability, acute sensitivity to ionizing radiation, and predisposition to malignancy. ${ }^{7,8}$ These have been well investigated by systemic deficiency of the protein; however, tissue-specific roles of ATM have not been well defined.

In this study, we investigated the effects of ATM deficiency on DC development from BM when treated with GM-CSF. Our results showed that $A T M-n u l l B M$ indicate lower proliferation and constitutive apoptosis, suggesting that ATM's fundamental and essential roles in the cell proliferation. This is at least partially due to reduced activation of Akt in ATM-null BM, but not Erk and p38 as previously shown in the development of neuronal stem cells. ${ }^{31}$ Furthermore, we found that the expression and activation of Jak2/STAT5 proteins, which are required for the development of $\mathrm{DC}$, are significantly delayed in ATM-null BM, compared with wild-type BM. These results illustrate DNA damage-independent function of ATM, and indeed, that GM-CSF-activated ATM does not phosphorylate SMC1 (Figure 1c), which is a substrate of ATM when cells are exposed to DNA damage. ${ }^{32}$

ATM is ubiquitously expressed in most of human tissues; however, there are some variations in levels of the protein during cellular differentiation and proliferation. ${ }^{11,13,15} \mathrm{We}$ found that ATM expression is extremely low in BM and is remarkably increased over a period of DC development when treated with GM-CSF (Figure 1a). Interestingly, in contrast to the levels of ATM protein, mRNA is expressed over 5 days, suggesting that the increase in ATM protein during DC development is due to posttranscriptional regulation. These results provide in vivo evidence that ATM is involved in regulating protein expression of its own as well as other signaling proteins identified in our studies such as Jak2 and STAT5. However, there are some proteins that are expressed in the early stage of BM, for example, SMC1, Erk, and p38 (Figures 1b, 5a and b), suggesting mRNA selectivity of posttranscriptional regulation by ATM. Specific mechanism remains to be elucidated.

In our studies, essential roles of ATM in DC development induced by GM-CSF were demonstrated by cell biological and genetic studies using an ATM kinase inhibitor, KU-55933, ${ }^{18}$ and ATM-deficient BM. First, we found that GM-CSF-induced DC development from wild-type BM was impaired when BM are treated with $\mathrm{KU}-55933$. We also showed that numbers of DC developed from ATM-null BM are significantly reduced, compared with those from wild-type BM. We consider that this is at least partially due to lower cell proliferation of ATM-null BM. Importantly, ATM deficiency does not completely inhibit DC development from BM (Figure 2a), indicating that ATM is not indispensable for BM to DC differentiation. Smaller numbers of ATM-null DC express high levels of $\mathrm{MHCII}$ and CD11c to the similar degree with wild-type DC. It has been shown that the high population of $\mathrm{DC}\left(\mathrm{MHCl}{ }^{\text {High }} \mathrm{CD} 11 \mathrm{c}^{\mathrm{High}}\right)$ is important to activate T cells. ${ }^{33}$ Because total numbers of DC (MHCII $^{\text {High }} / \mathrm{CD} 11 \mathrm{c}^{\text {High }}$ ) developed from ATM-null BM is much less than wild-type DC, it might explain the impaired capacity to activate T cells by ATM-null DC (Figure 3).

Akt has been implicated in growth factor signaling, cell survival, proliferation, metabolism, and tumorigenesis. ${ }^{34}$ In particular, GM-CSF-induced activation of Akt is essential for full differentiation and generation of immature monocytederived DC. ${ }^{26}$ Recent studies have provided evidence that ATM functions upstream of Akt and phosphorylates Ser473 of Akt in response to insulin or ionizing radiation. ${ }^{35,36}$ It has also been shown that ATM inhibitor KU-55933 suppresses cell proliferation induced by insulin or insulin-like growth factor-1. ${ }^{37}$ Further, defective proliferation in ATM-null neural stem cells can be restored by Akt activation. ${ }^{38}$ Consistent with these previous studies, we found the functional interaction between Akt and ATM in BM in the current studies. GM-CSFinduced phosphorylation of Akt at Ser473 was reduced in wild-type BM treated with KU55933 as well as ATM-null BM. Levels of the protein were also lowered in ATM-null BM, and Akt inhibitor impaired DC development in a dose-dependent 
manner (Figures $5 \mathrm{a}-\mathrm{c}$ ). These results suggest that ATM determines not only phosphorylation of Akt at Ser473 but also the levels of the protein by posttranscriptional mechanism (Figures $6 a$ and b). Given that retroviral expression of dominant-active Akt in ATM-null BM increased the number of $\mathrm{MHCI}{ }^{\text {High }} \mathrm{BM}$, signaling cascade from ATM to Akt is critical in $\mathrm{DC}$ development.

GM-CSF activation of Jak/STAT signaling pathways that include Jak2 and STAT5 has been extensively studied. ${ }^{39} \mathrm{We}$ found that the expression of STAT5 appears at D6 in wild-type BM culture, but undetectable in ATM-null BM. Infection of ATM-null BM with GFP-STAT5 retrovirus at D3 can rescue the development of MHCll-positive $\mathrm{DC}$ to the similar degree of that of wild-type BM. These results suggest that the expression of STAT5 is crucial for DC development. Notably, no significant differences in STAT5A and Akt1 mRNA were observed from D3 to D8, we consider that protein expression is regulated in posttranscriptional mechanisms. We are currently exploring whether STAT5 regulation of subsets of genes and micro RNAs is essential for DC development.

Recent studies have suggested non-nuclear functions of ATM. ${ }^{40,41}$ Our current studies indicate that subcellular localization is changed from cytoplasm to nuclear in the course of DC development; however, substrates of cytoplasmic ATM remain to be identified. Given that SMC1 is not phosphorylated when ATM is activated by GM-CSF, it is conceivable that ATM regulates an unknown pathway(s) in BM. Other evidence is that, as Kastan's group ${ }^{12}$ has shown, ATM is involved in initiation of protein translation by phosphorylating 4EBP1. Our results showed in vivo that phosphorylation of 4EBP1 by several kinases including ATM is important to release the protein from elF4E, resulting in active translation regulated by a protein complex including elF4E (Figure 7). Interestingly, 4EBP1 becomes phosphorylated at D8 in ATM-null BM, indicating that an unknown kinase(s) phosphorylates 4EBP1 in the absence of ATM. Our results also indicate that ATM deficiency causes lowered expression of mTOR that has been implicated in the maturation and function of $\mathrm{DC}$ in vitro and in vivo, together with PI3K. ${ }^{42-44}$ Given the function of mTOR pathway to regulate protein translation, ${ }^{45}$ our results strongly suggest that reduced cell proliferation is due to lowered expression and impaired activation of Akt, and that delayed expression of mTOR subsequently causes delayed expression of Jak2 and STAT5, which are crucial for DC development and functions. ${ }^{46,47}$

In conclusion, our studies demonstrate in vivo evidence that ATM deficiency causes lowered expression of proteins involved in cell proliferation and DC development from BM because of impaired protein translation machinery, particularly in early stage of the development (Figure 8). It is assumed that ATM-dependent increase in STAT5 and Jak2 are essential for the later stage of this process. Abnormality of DC development observed in ATM-deficient mice might explain the defect and malfunction of immune system of ATM patients and their multiple disease status.

\section{Materials and Methods}

Mice. C57BL/6J and ATM $-I+$ mice (129S6/SvEvTac-ATM ${ }^{\text {m1-Awb }}$ ) were purchased from The Jackson Laboratory (Bar Harbor, ME, USA). ATM $-1+$ mice were intercrossed to obtain homozygous progeny. ATM knockout mice were used and littermate mice $(A T M+1+)$ from same cage were used as wild-type control. SJL/J mice were purchased from Jackson Laboratory to isolate allogeneic $T$ cells. All mice were maintained in the pathogen-free animal facility of Roswell Park Cancer Institute.

Generation of BM-derived DC and macrophages. BM-derived DCs were generated as described. ${ }^{48}$ Briefly, BM cells were purified from femurs and tibiae of 5-10-week-old male mice in RPMI 10 media (RPMI 10) supplemented with $10 \%$ heat-inactivated FBS, penicillin/streptomycin, and L-glutamin (all from Invitrogen, Carlsbad, CA, USA). Cells were cultured for 9 days in RPMI 10 containing GM-CSF (20 ng/ml, PeproTech, Rocky Hill, NJ, USA). On Day 2, 4, and 5 , non-adherent cells were removed and used as BM-derived DC for experiments. To isolate the BM-derived macrophages, adherent cells were harvested using scrapper. ${ }^{1} \mathrm{CD} 11 \mathrm{C}$ and $\mathrm{MHCll}$ proteins have been used to determine BM differentiation; granulocytes and myeloid precursors $\left(\mathrm{CD}_{11 \mathrm{C}^{-}} \mathrm{MHCll}^{-}\right)$, monocytes/macrophages (CD11 $\left.{ }^{\text {Low } M H C I I}{ }^{\text {Low }}\right)$, immature DC (CD11 ${ }^{\text {High }}$ MHCII $\left.^{\text {Medium }}\right)$, and mature $\mathrm{DC}\left(\mathrm{CD} 11 \mathrm{c}^{\text {High }} \mathrm{MHCI}{ }^{\text {High }}\right){ }^{49}$

Chemical reagents. MG132 (50, 200, and $500 \mathrm{nM})$ and KU-55399 $(1 \sim 5 \mu \mathrm{M})$ were purchased from Tocris (Ellisville, MO, USA) and dissolved in DMSO. Akt inhibitor IV (1 or $2 \mu \mathrm{M})$ was purchased from Calbiochem (Billerica, MA, USA). Neocarzinostatin (NCS, $0.5 \mu \mathrm{g} / \mathrm{ml})$ and lipopolysccharide (LPS, 1 and $2 \mu \mathrm{g} / \mathrm{ml}$ ) were purchased from Sigma-Aldrich (St. Louis, MO, USA).

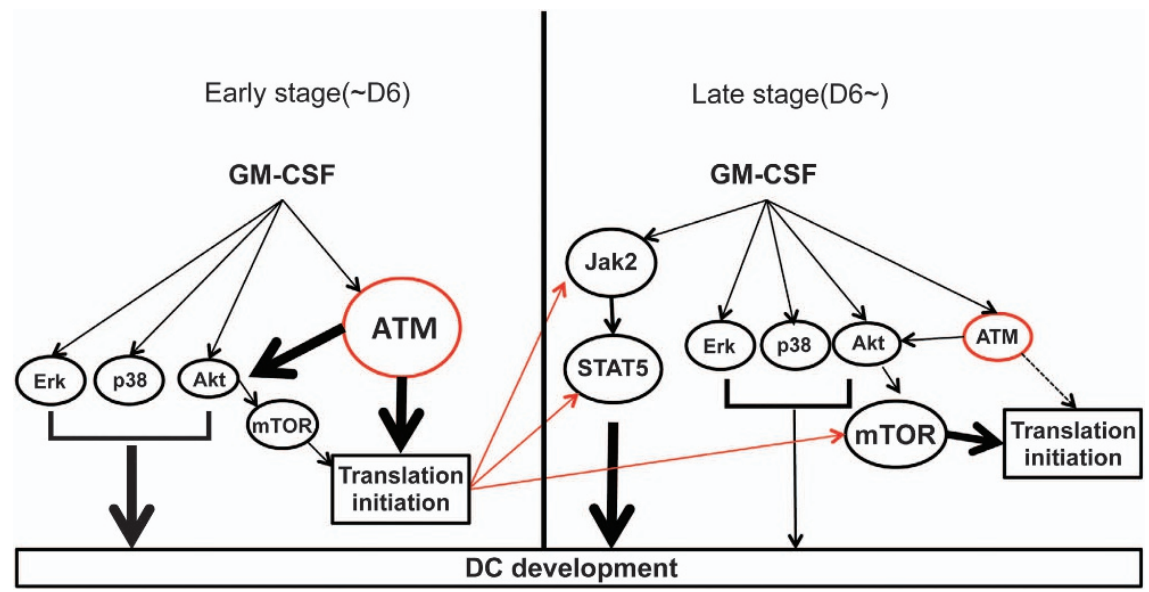

Figure 8 Model of the roles of ATM in BM differentiation to DC induced by GM-CSF. At early stage ( D6), ATM transduces signaling from GM-CSF to Akt, leading to efficient translation of proteins essential in development of DC. At late stage, ATM-dependent expression of Jak2/STAT5 is essential for maturation of DC 
Antibodies and flow cytometric analysis. All antibodies conjugated to fluorochromes for flow cytometry were purchased from eBiosciences (San Diego, CA, USA), those including the following: MHCII (I-A/I-E)-APC, CD86 (B7-2)-APC, CD11c-FITC, CD3e-FITC, and CD71 (transferring receptor)-APC. Cultured BM-derived cells were harvested and labeled with two antibodies (anti-CD11c and anti-MHCII or anti-CD86), and then analyzed by flow cytometry.

RNA purification and RT-PCR. Total RNA was isolated from GM-CSFtreated BM using TRIzole reagent (Invitrogen), according to the manufacturer's instructions. First-strand CDNA was synthesized by MMLV reverse transcriptase (Invitrogen) and oligo(dT) ${ }_{18}$ (IDT, Coralville, IA, USA), from $4 \mu \mathrm{g}$ total RNA. Primer sequences used were as follows; ATM (5'-AACTCTTGTCCGGTGTTCACGTCT-3' and $5^{\prime}$-ACTTTGGCTCTCTCCAGGTTCGTT-3'); STAT5A (5'-TGCGCCAGATG CAAGTGTTGTATG- $3^{\prime}$ and $5^{\prime}$-TGTTCTGGAGCTGTGTGGCATAGT-3'); Akt1 (5'-ACGGGCACATCAAGATAACGGACT-3' and 5'-AAGGTGGGCTCAGCTTCTT CTCAT- $3^{\prime}$ ); GAPDH (5'-AAGGTCGGAGTCAACGGATTTGGT-3' and $5^{\prime}$-AGTG ATGGCATGGACTGTGGTCAT-3'). GAPDH expression was assessed as an internal reference for normalization.

Allogeneic mixed lymphocyte reaction (MLR). The capacity of DC to activate $T$ cells was measured by MLR assay as described previously. ${ }^{49}$ Briefly, DC were harvested from D9 BM culture and used as stimulator cells to activate responder ( $T$ cells). T cells were isolated from lymph node in RPMI 10 media. Cells were seeded into round-bottom 96-well plates at a concentration of $2 \times 10^{5}$ cells/well. Numbers of stimulator cells was decided depending on the ratio of stimulator/responder cells. Cells were harvested after $96 \mathrm{~h}$, labeled using CD3eFITC and CD71 antibodies, and then analyzed by flow cytometry. The expression of the transferring receptor (CD71) was used to determine T-cell proliferation as previously described. ${ }^{49}$ The percentage of $\mathrm{CD}^{+}{ }^{+} \mathrm{CD} 71^{+}$cell was expressed as the activating capacity of DC.

Cell proliferation and apoptosis analysis. Cultured BM were washed and diluted with $0.4 \%$ trypan blue solution. Trypan-blue-negative cells were counted as living cells in a Reichert counting chamber (Buffalo, NY, USA). Apoptosis was determined by Annexin V-APC Apoptosis Detection Kit (eBiosciences) according to manufacturer's protocol as described. ${ }^{17}$ Propidium iodide was purchased from EMD Chemicals (Gibbstown, NJ, USA) and used to distinguish between viable, early apoptotic and necrotic, or late-apoptotic cells.

Western blotting analysis. Cells were harvested from wild-type and ATM-null BM culture at indicated days, and then lysed in ice-cold lysis buffer ( $50 \mathrm{mM}$ Tris-HCl (pH 7.6), $150 \mathrm{mM} \mathrm{NaCl}, 1 \mathrm{mM}$ EDTA (pH 8.0), $20 \mathrm{mM} \mathrm{NaF}, 1 \mathrm{mM}$ $\mathrm{Na}_{3} \mathrm{VO}_{4}, 1 \% \mathrm{NP} 40,0.5 \mathrm{mM}$ dithiothreitol) in the presence of protease-inhibitor mix (leupeptin, aprotinin, and PMSF, $10 \mu \mathrm{g} / \mathrm{ml}$, respectively). Total cell lysate $(10 \mu \mathrm{g})$ was loaded and separated by $6 \sim 15 \%$ SDS-PAGE gels. Antibodies for ATM (GeneTex, Irvine, CA, USA), Akt, Erk, H2AX (Santa Cruz Biotechnology, Santa Cruz, CA, USA), p38, STAT5, NUP98, Histone H3, elF4E, and 4EBP1 (Cell Signaling Technology, Danvers, MA, USA) were used to detect total proteins. Specific anti-phosphorylation antibodies were used against phosphor-H2AX $(\gamma \mathrm{H} 2 \mathrm{AX}$, Novus Biologicals, Littleton, CO, USA), phospho-Akt (Ser473), phospho-p44/p42 (Thr202/Tyr204), phospho-p38 (Thr180/Try182), and phosphor-STAT5 (Tyr694, all from Cell signaling Technology). The antibody for phosphorylated mouse ATM (S1987) was purchased from R\&D systems (Minneapolis, MN, USA). Specificities of ATM antibodies used in this study are shown in Supplementary Figure S3. Anti-actin antibody (Santa Cruz Biotechnology) was used to validate protein amount. To analyze the localization of ATM in BM, cytoplasmic extract and nuclear extract were prepared as described. ${ }^{50}$

eIF4E pull-down assay. Total cell lysates from wild-type and ATM-null BMDC (200 $\mu \mathrm{g} / \mathrm{sample})$ were incubated with $\mathrm{m} 7$-GTP-Sepharose bead (GE healthcare, Pittsburgh, PA, USA) for $2 \mathrm{~h}$, then washed with lysis buffer. The SDS sample loading buffer (2X, Bio-Rad, Hercules, CA, USA) was added to the beads, and the samples were subjected to western blot with antibodies against elF4E and 4EBP1 (Cell Signaling Technology).

Retrovirus preparation and infection of BM. Retroviral-expressing vectors of wild-type STAT5A (pMSCV-STAT5A-GFP) and GFP-only (pMSCVGFP) were provided by Dr. Hennighausen (Laboratory of Genetics and Physiology, National Institute of Diabetes and Digestive and Kidney Diseases,
National Institute of Health, Bethesda, MD, USA). Akt-IRES-GFP (active Akt) vector was the gift of Dr. Yukiko Gotoh (University of Tokyo). ${ }^{27}$ For making retrovirus, Plate-E cells were transfected with retroviral vectors and $\mathrm{pEco}$ (the plasmid containing packaging sequences) using LipoD293 transfection reagent (SignaGen Laboratories, Rockville, MD, USA). All supernatants were collected $48 \mathrm{~h}$ after transfection and passed through $0.45 \mu \mathrm{m}$ filter, followed by $1000 \mathrm{~g}$ centrifugation. Retrovirus was added into BM culture at D2 (active Akt) or D3 (STAT5A) in the presence of $4 \mu \mathrm{g} / \mathrm{ml}$ polybrene (Sigma-Aldrich). Cells were harvested at D6 (active Akt) or D8 (STAT5A), washed with PBS, stained with antiMHCII-APC, and then subjected to flow cytometry. GFP-positive and -negative cells were gated, respectively, and $\mathrm{MHCll}$ expression was analyzed.

\section{Conflict of interest}

The authors declare no conflict of interest.

Acknowledgements. We thank all the members of the Ouchi laboratory for helpful discussion. We also thank Drs. Yukiko Gotoh (University of Tokyo) and Lothar Hennighausen (NIDDK/NIH) for providing us with Akt and STAT5 expression vectors, respectively. This work was in part supported by R01CA90631 (NCl) and Susan G. Komen Breast Cancer Grant (T.O.).

1. Inaba K, Inaba M, Romani N, Aya H, Deguchi M, Ikehara S et al. Generation of large numbers of dendritic cells from mouse bone marrow cultures supplemented with granulocyte/macrophage colony-stimulating factor. J Exp Med 1992; 176: 1693-1702.

2. Gilliet M, Boonstra A, Paturel C, Antonenko S, Xu XL, Trinchieri $G$ et al. The development of murine plasmacytoid dendritic cell precursors is differentially regulated by FLT3-ligand and granulocyte/macrophage colony-stimulating factor. $J$ Exp Med 2002; 195: 953-958.

3. Banchereau J, Briere F, Caux C, Davoust J, Lebecque S, Liu YJ et al. Immunobiology of dendritic cells. Annu Rev Immunol 2000; 18: 767-811.

4. Derheimer FA, Kastan MB. Multiple roles of ATM in monitoring and maintaining DNA integrity. FEBS Lett 2010; 584: 3675-3681.

5. Lavin MF, Kozlov S. ATM activation and DNA damage response. Cell Cycle 2007; 6: 931-942.

6. Guo Z, Kozlov S, Lavin MF, Person MD, Paull TT. ATM activation by oxidative stress Science 2010; 330: 517-521.

7. Xu Y, Ashley T, Brainerd EE, Bronson RT, Meyn MS, Baltimore D. Targeted disruption of ATM leads to growth retardation, chromosomal fragmentation during meiosis, immune defects, and thymic lymphoma. Genes Dev 1996; 10: 2411-2422.

8. Barlow C, Hirotsune S, Paylor R, Liyanage M, Eckhaus M, Collins F et al. Atm-deficient mice: a paradigm of ataxia telangiectasia. Cell 1996; 86: 159-171.

9. Bagley J, Cortes ML, Breakefield XO, lacomini J. Bone marrow transplantation restores immune system function and prevents lymphoma in Atm-deficient mice. Blood 2004; 104: 572-578.

10. Rasheed N, Wang X, Niu QT, Yeh J, Li B. Atm-deficient mice: an osteoporosis model with defective osteoblast differentiation and increased osteoclastogenesis. Hum Mol Genet 2006; 15: 1938-1948.

11. Fukao T, Kaneko H, Birrell G, Gatei M, Tashita H, Yoshida T et al. ATM is upregulated during the mitogenic response in peripheral blood mononuclear cells. Blood 1999; 94: 1998-2006.

12. Yang $D Q$, Kastan MB. Participation of $A T M$ in insulin signalling through phosphorylation of elF-4E-binding protein 1. Nat Cell Biol 2000; 2: 893-898.

13. Starczynski J, Simmons W, Flavell JR, Byrd PJ, Stewart GS, Kullar HS et al. Variations in ATM protein expression during normal lymphoid differentiation and among B-cell-derived neoplasias. Am J Pathol 2003; 163: 423-432.

14. Geissmann F, Manz MG, Jung S, Sieweke MH, Merad M, Ley K. Development of monocytes, macrophages, and dendritic cells. Science 2010; 327: 656-661.

15. Clarke RA, Kairouz R, Watters D, Lavin MF, Kearsley JH, Lee CS. Upregulation of ATM in sclerosing adenosis of the breast. Mol Pathol 1998; 51: 224-226.

16. Abraham $P$, Indirani $K$, Desigamani $K$. Nitro-arginine methyl ester, a non-selective inhibitor of nitric oxide synthase reduces ibuprofen-induced gastric mucosal injury in the rat. Dig Dis Sci 2005; 50: 1632-1640.

17. So EY, Ausman M, Saeki T, Ouchi T. Phosphorylation of SMC1 by ATR is required for desferrioxamine (DFO)-induced apoptosis. Cell Death Dis 2011; 2: e128.

18. Hickson I, Zhao Y, Richardson CJ, Green SJ, Martin NM, Orr Al et al. Identification and characterization of a novel and specific inhibitor of the ataxia-telangiectasia mutated kinase ATM. Cancer Res 2004; 64: 9152-9159.

19. Cella M, Sallusto F, Lanzavecchia A. Origin, maturation and antigen presenting function of dendritic cells. Current Opin Immunol 1997; 9: 10-16. 
20. Trombetta ES, Mellman I. Cell biology of antigen processing in vitro and in vivo. Annu Rev Immunol 2005; 23: 975-1028.

21. Strong DM, Ahmed AA, Thurman GB, Sell KW. In vitro stimulation of murine spleen cells using a microculture system and a multiple automated sample harvester. J Immunol Methods 1973; 2: 279-291.

22. Zheng Y, Collins SL, Lutz MA, Allen AN, Kole TP, Zarek PE et al. A role for mammalian target of rapamycin in regulating $T$ cell activation versus anergy. $J$ Immunol 2007; 178: 2163-2170.

23. Pattanapanyasat K, Hoy TG. Expression of cell surface transferrin receptor and intracellular ferritin after in vitro stimulation of peripheral blood $T$ lymphocytes. Eur J Haematol 1991; 47: 140-145.

24. Labeur MS, Roters B, Pers B, Mehling A, Luger TA, Schwarz T et al. Generation of tumor immunity by bone marrow-derived dendritic cells correlates with dendritic cell maturation stage. J Immunol 1999; 162: 168-175.

25. Lapointe R, Toso JF, Butts C, Young HA, Hwu P. Human dendritic cells require multiple activation signals for the efficient generation of tumor antigen-specific $T$ lymphocytes. Eur J Immunol 2000; 30: 3291-3298.

26. Xie J, Qian J, Yang J, Wang S, Freeman ME, Yi Q. Critical roles of Raf/MEK/ERK and PI3K/AKT signaling and inactivation of p38 MAP kinase in the differentiation and survival of monocyte-derived immature dendritic cells. Exp Hematol 2005; 33: 564-572.

27. Oishi K, Watatani K, Itoh Y, Okano H, Guillemot F, Nakajima K et al. Selective induction of neocortical GABAergic neurons by the PDK1-Akt pathway through activation of Mash1. Proc Natl Acad Sci USA 2009; 106: 13064-13069.

28. Esashi E, Wang YH, Perng O, Qin XF, Liu YJ, Watowich SS et al. The signal transducer STAT5 inhibits plasmacytoid dendritic cell development by suppressing transcription facto IRF8. Immunity 2008; 28: 509-520.

29. Gingras AC, Gygi SP, Raught B, Polakiewicz RD, Abraham RT, Hoekstra MF et al Regulation of 4E-BP1 phosphorylation: a novel two-step mechanism. Genes Dev 1999; 13 1422-1437.

30. Shiloh Y, Kastan MB. ATM: genome stability, neuronal development, and cancer cross paths. Adv Cancer Res 2001; 83: 209-254.

31. Kim J, Wong PK. Loss of ATM impairs proliferation of neural stem cells through oxidative stress-mediated p38 MAPK signaling. Stem Cells 2009; 27: 1987-1998.

32. Kitagawa R, Bakkenist CJ, McKinnon PJ, Kastan MB. Phosphorylation of SMC1 is critical downstream event in the ATM-NBS1-BRCA1 pathway. Genes Dev 2004; 18 : 1423-1438.

33. Bosch B, Heipertz EL, Drake JR, Roche PA. Major histocompatibility complex (MHC) class II-peptide complexes arrive at the plasma membrane in cholesterol-rich microclusters. J Biol Chem 2013; 288: 13236-13242.

34. Xu N, Lao Y, Zhang Y, Gillespie DA. Akt: a double-edged sword in cell proliferation and genome stability. J Oncol 2012; 2012: 951724.

35. Viniegra JG, Martínez $N$, Modirassari $P$, Hernández Losa J, Parada Cobo Sánchez-Arévalo Lobo VJ et al. Full activation of PKB/Akt in response to insulin or ionizing radiation is mediated through ATM. J Biol Chem 2005; 280: 4029-4036.

36. Fraser M, Harding SM, Zhao H, Coackley $\mathrm{C}$, Durocher D, Bristow RG. MRE11 promotes AKT phosphorylation in direct response to DNA double-strand breaks. Cell Cycle 2011; 10 2218-2232.

37. Li Y, Yang DQ. The ATM inhibitor KU-55933 suppresses cell proliferation and induces apoptosis by blocking Akt in cancer cells with overactivated Akt. Mol Cancer Ther 2010; 9 113-125.
38. Kim J, Hwangbo J, Wong PK. p38 MAPK-Mediated Bmi-1 down-regulation and defective proliferation in ATM-deficient neural stem cells can be restored by Akt activation. PLoS One 2011; 6: e16615.

39. Hercus TR, Thomas D, Guthridge MA, Ekert PG, King-Scott J, Parker MW et al. The granulocyte-macrophage colony-stimulating factor receptor: linking its structure to cell signaling and its role in disease. Blood 2009; 114: 1289-1298.

40. Valentin-Vega YA, Maclean KH, Tait-Mulder J, Milasta S, Steeves M, Dorsey FC et al. Mitochondrial dysfunction in ataxia-telangiectasia. Blood 2012; 119: 1490-1500.

41. Ambrose M, Goldstine JV, Gatti RA. Intrinsic mitochondrial dysfunction in ATM-deficient lymphoblastoid cells. Hum Mol Genet 2007; 16: 2154-2164.

42. Lelouard H, Schmidt EK, Camosseto V, Clavarino G, Ceppi M, Hsu HT et al. Regulation of translation is required for dendritic cell function and survival during activation. $J$ Cell Biol 2007; 179: 1427-1439.

43. Hackstein H, Taner T, Zahorchak AF, Morelli AE, Logar AJ, Gessner A et al. Rapamycin inhibits IL-4-induced dendritic cell maturation in vitro and dendritic cell mobilization and function in vivo. Blood 2003; 101: 4457-4463.

44. Sathaliyawala T, O'Gorman WE, Greter M, Bogunovic M, Konjufca V, Hou ZE et al. Mammalian target of rapamycin controls dendritic cell development downstream of Flt3 ligand signaling. Immunity 2010; 33: 597-606.

45. Ma XM, Blenis J. Molecular mechanisms of mTOR-mediated translational control. Nature reviews. Mol Cell Biol 2009; 10: 307-318.

46. Zhong J, Yang P, Muta K, Dong R, Marrero M, Gong $\mathrm{F}$ et al. Loss of Jak2 selectively suppresses DC-mediated innate immune response and protects mice from lethal dose of LPS-induced septic shock. PLoS One 2010; 5: e9593.

47. Bell BD, Kitajima M, Larson RP, Stoklasek TA, Dang K, Sakamoto K et al. The transcription factor STAT5 is critical in dendritic cells for the development of TH2 but not TH1 responses. Nat Immunol 2013; 14: 364-371.

48. Lutz MB, Kukutsch N, Ogilvie AL, Rössner S, Koch F, Romani N et al. An advanced culture method for generating large quantities of highly pure dendritic cells from mouse bone marrow. J Immunol Methods 1999; 223: 77-92.

49. Nikolic T, Bunk M, Drexhage HA, Leenen PJ. Bone marrow precursors of nonobese diabetic mice develop into defective macrophage-like dendritic cells in vitro. $J$ Immunol 2004; 173: 4342-4351.

50. Nakahira M, Ahn HJ, Park WR, Gao P, Tomura M, Park CS et al. Synergy of IL-12 and IL-18 for IFN-gamma gene expression: IL-12-induced STAT4 contributes to IFN-gamma promoter activation by up-regulating the binding activity of $\mathrm{IL}$-18-induced activator protein 1. J Immunol 2002; 168: 1146-1153.

Cell Death and Disease is an open-access journal BY ${ }^{2}$ SA
licensed under a Creative Commons Attribution-NonCommercialShareAlike 3.0 Unported License. The images or other third party material in this article are included in the article's Creative Commons license, unless indicated otherwise in the credit line; if the material is not included under the Creative Commons license, users will need to obtain permission from the license holder to reproduce the material. To view a copy of this license, visit http://creativecommons.org/licenses/ by-nc-sa/3.0/ 